\title{
Business-to-business electronic commerce success: a supply network perspective
}

\begin{abstract}
DeLone and McLean (2004) have advanced an electronic commerce (EC) success model and suggest that it can be extended to investigating EC success in different contexts. However, the EC success model has not been empirically validated in the context of business-tobusiness (B2B) EC. The purpose of this study is to gain a better understanding of EC value and success within the B2B environment. Accordingly, we introduce an extended version of DeLone and McLean's (2004) EC success model, and test hypotheses regarding the associations between various success dimensions using the data collected from 122 supply chain units. In addition to providing support for most of the hypotheses suggested by DeLone and McLean's (2004) EC success model, our results indicate that other success dimensions, such as EC readiness, must be considered for successful EC in B2B environments. The research findings provide practitioners with clarity on the levers of B2B e-commerce success within the supply chain unit level of analysis. Overall, the study's results contribute to theoretical development in the area of business value creation and EC success, and present a basis for further research in these fields.
\end{abstract}

Keyword: EC success; Net benefits; Business performance; Supply network; E-commerce; Satisfaction 